\title{
Mammalian meiosis is more conserved by sex than by species: conserved co-expression networks of meiotic prophase
}

\author{
Yongchun $\mathrm{Su}^{1}$, Yunfei $\mathrm{Li}^{1,2}$ and Ping $\mathrm{Ye}^{1,3}$ \\ ${ }^{1}$ School of Molecular Biosciences, ${ }^{2}$ Department of Statistics and ${ }^{3}$ Center for Reproductive Biology, Washington State \\ University, PO Box 647520, Pullman, Washington 99164, USA
}

Correspondence should be addressed to P Ye at School of Molecular Biosciences, Washington State University; Email: pye@wsu.edu

Y Su and Y Li contributed equally to this work

\begin{abstract}
Despite the importance of meiosis to human reproduction, we know remarkably little about the genes and pathways that regulate meiotic progression through prophase in any mammalian species. Microarray expression profiles of mammalian gonads provide a valuable resource for probing gene networks. However, expression studies are confounded by mixed germ cell and somatic cell populations in the gonad and asynchronous germ cell populations. Further, widely used clustering methods for analyzing microarray profiles are unable to prioritize candidate genes for testing. To derive a comprehensive understanding of gene expression in mammalian meiotic prophase, we constructed conserved co-expression networks by linking expression profiles of male and female gonads across mouse and human. We demonstrate that conserved gene co-expression dramatically improved the accuracy of detecting known meiotic genes compared with using co-expression in individual studies. Interestingly, our results indicate that meiotic prophase is more conserved by sex than by species. The co-expression networks allowed us to identify genes involved in meiotic recombination, chromatin cohesion, and piRNA metabolism. Further, we were able to prioritize candidate genes based on quantitative co-expression links with known meiotic genes. Literature studies of these candidate genes suggest that some are human disease genes while others are associated with mammalian gonads. In conclusion, our co-expression networks provide a systematic understanding of cross-sex and cross-species conservations observed during meiotic prophase. This approach further allows us to prioritize candidate meiotic genes for in-depth mechanistic studies in the future.
\end{abstract}

Reproduction (2011) 142 675-687

\section{Introduction}

Meiosis, the process by which haploid gametes are produced, is essential to human reproduction. The regulation of meiosis is highly complex and is further complicated by sexual dimorphism. Although meiotic phases are essentially the same in both sexes, fundamental differences exist in timing, outcome, and checkpoint control (Morelli \& Cohen 2005, Bowles \& Koopman 2007, Kimble \& Page 2007, Hunt \& Hassold 2008, Handel \& Schimenti 2010). In the female, all oocytes enter meiosis semi-synchronously during a narrow window of fetal development. Meiosis arrests before birth at the end of prophase and resumes at puberty during each ovulation cycle. One egg is produced at the end of female meiosis. In contrast, meiosis in the male begins in the juvenile testis and is a continuous and unsynchronized process. Four sperms are generated from each male meiosis cycle. Any error during meiosis jeopardizes the quality and quantity of gametes and can lead to infertility, birth defects, or miscarriages. Meiotic prophase is a particularly vulnerable time for errors because homologous chromosomes pair and exchange genetic information. Studies of mouse mutants for meiotic genes have revealed different levels of checkpoint control in males and females. Due to more stringent control mechanisms in the male that eliminate cells with errors, the probability of producing an aneuploid gamete is at least an order of magnitude greater in the female (Hunt \& Hassold 2002, Morelli \& Cohen 2005).

Despite the importance of meiosis to human reproduction, few genes are known to be critical to meiotic progression through prophase in mammals. Further, virtually no data exist to describe interactions between meiotic genes or functional pathways connecting them. Indeed, the overall structure of the functional and regulatory pathways directing germ cells into the meiotic program remains completely undefined. Identifying gene networks and pathways involved in meiosis is 
necessary for bridging the knowledge gap to address health issues such as infertility and birth defects.

One resource that may allow the identification of gene networks is microarray, which provides a platform to evaluate genome-wide expression. Reproductive tissuespecific microarray profiles allow us to probe pathways and networks that may govern meiotic dynamics (Schultz et al. 2003, Shima et al. 2004, Small et al. 2005, Chalmel et al. 2007, Olesen et al. 2007, Houmard et al. 2009, Lawson et al. 2011, Rolland et al. 2011). However, the analysis has been limited to simple clustering of individual expression profiles, preventing construction of gene networks and prioritization of candidate genes for testing. Further, the meiotic process conserved between males and females has not been systematically investigated from these expression profiles.

Although studying meiosis in a single sex and species is important, cross-sex and cross-species investigation of meiotic pathways can help in identifying the most conserved players as well as in making inferences on human meiotic defects. In this study, our objective was to derive a comprehensive understanding of meiotic prophase genes conserved across species and sex. To this end, we constructed conserved gene co-expression networks by integrating microarray profiles. We focused on time-course expression profiles covering meiotic prophase during fetal oogenesis and the first wave of spermatogenesis in both human and mouse (Shima et al. 2004, Small et al. 2005, Houmard et al. 2009), since the mouse serves as a genetically tractable mammalian model for investigating human meiosis. Prophase is the most synchronized meiotic process, providing a favorable temporal window for investigating genetic control of meiosis in both sexes. Further, prophase is the most defining stage of meiosis, during which homologous chromosomes pair and undergo recombination. Our conserved co-expression networks provide a systematic understanding of potential interactions between genes in prophase. Cross-species and cross-sex inference allowed us to identify core components of meiotic machinery and to prioritize candidate genes for experimental studies in mice and humans.

\section{Results \\ Conserved co-expression networks of mammalian meiotic prophase}

To construct conserved meiotic pathways in mammals, we took advantage of available prophase expression profiles from males and females across human and mouse (Shima et al. 2004, Small et al. 2005, Houmard et al. 2009). We identified 16376 genes conserved between human and mouse (called $\mathrm{MHs}$ ) and investigated meiotic expression of these MHs (Table 1; Ostlund et al. 2010). Co-expression of $\mathrm{MH}$ gene pairs in prophase
Table $1 \mathrm{MHs}$ are genes conserved between mouse and human.

\begin{tabular}{lccc}
\hline & Gene number & Genome coverage $^{\mathrm{a}}(\%)$ & Genes per $\mathbf{M H}$ \\
\hline $\mathrm{MH}$ & 16376 & - & - \\
Mouse & 16566 & 71 & 1.01 \\
Human & 16700 & 77 & 1.02 \\
\hline
\end{tabular}

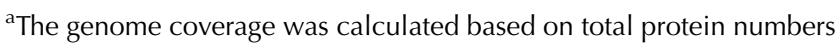
in the mouse (23 497) and the human (21 673) from InParanoid Version 7.0 (Ostlund et al. 2010).

was first quantified from three individual microarray studies on the mouse postnatal testis, mouse embryonic ovary, and human fetal ovary using the Pearson correlation and a resulting standard z-score. Microarray data are currently unavailable for the human male. Then, we averaged $z$-scores across sex and species to determine conserved co-expression. We have developed an efficient 'divide and conquer' algorithm to process hundreds of millions of gene pairs using a standard desktop computer. MH gene pairs with average $z$-scores greater than a threshold can be connected to form a network. In this way, we constructed three co-expression networks of mammalian meiotic prophase: a network conserved between male mouse and female mouse $\left(M_{m}-M_{f}\right)$, a network conserved between female mouse and female human $\left(M_{f}-H_{f}\right)$, and a network conserved among male mouse, female mouse, and female human $\left(M_{m}-M_{f}-H_{f}\right.$ Fig. 1$)$.

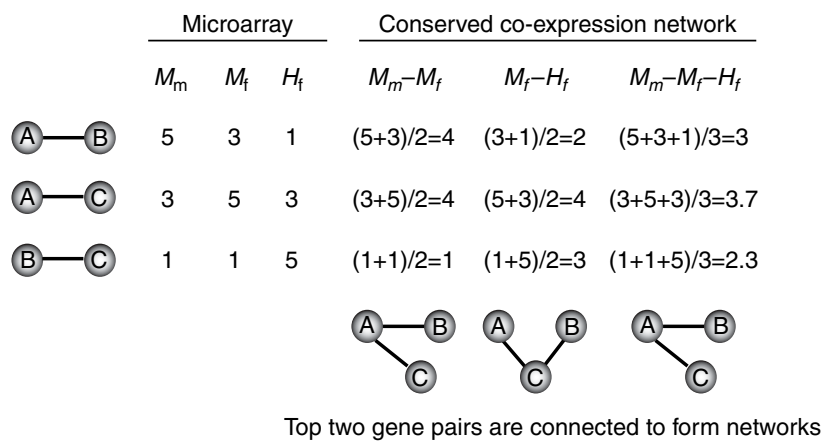

Figure 1 Construction of conserved co-expression networks of mammalian meiotic prophase. Co-expression of two genes was calculated from each of three time-course microarray studies on male mouse $\left(\mathcal{M}_{m}\right)$, female mouse $\left(\mathcal{M}_{f}\right)$, and female human $\left(H_{f}\right)$ using a standard $z$-score. For instance, the standard $z$-score for genes $A$ and $B$ is equal to 5 in the male mouse study. To identify conserved co-expression across species and sex, we averaged standard $z$-scores from different microarray studies for the same gene pair. For instance, the average $z$-score for genes $A$ and $B$ between male mouse and female mouse equals 4 by taking the average of 5 and 3 . The top two gene pairs with greater $z$-scores are connected to form a network. This leads to the construction of three networks of mammalian meiotic prophase: a co-expression network conserved between male mouse and female mouse $\left(\mathcal{M}_{m}-\mathcal{M}_{f}\right)$, a co-expression network conserved between female mouse and female human $\left(M_{f}-H_{f}\right)$, and a co-expression network conserved among male mouse, female mouse, and female human $\left(M_{m}-M_{f}-H_{f}\right)$. 


\section{Validation of conserved co-expression networks}

We used known meiotic genes annotated by Gene Ontology (GO:0007126) as the standard to evaluate conserved co-expression networks. We created the precision-coverage curve, the appropriate metric to determine the performance of co-expression networks in identifying known meiotic genes (Fig. 2). All gene pairs in each network were sorted in descending order of average $z$-score, and precision and coverage were calculated in 200-pair increments. Precision is the ratio of known meiotic genes to all genes among co-expression pairs, while coverage is the number of known meiotic genes (the numerator of precision). Perfect precision $(=1)$ means every gene among co-expression pairs is a meiotic gene. Perfect coverage means genes among co-expression pairs cover all known meiotic genes. It is observed that low precision ( $y$-axis) is due to the small number of known meiotic genes ( $x$-axis) compared with the total number of genes genomewide. There are $\sim 80$ meiotic genes among $16376 \mathrm{MHs}$. Thus, the precision of identifying meiotic genes at random is $\sim 0.005$.

When we used mouse meiotic genes to evaluate conserved co-expression, we found that top pairs in all three networks can recover significant numbers of known meiotic genes compared with the randomized networks (Fig. 2A). In particular, the top 200 gene pairs (the first data point from the left) in the $M_{m}-M_{t}-H_{f}$ network exhibit over an eightfold increase in precision. This suggests that multiple species integration can improve the accuracy of meiotic gene identification. The top 200 gene pairs in $M_{m}-M_{f}$ and $M_{f}-H_{f}$ show a three- and five-fold increase in precision, respectively, compared with the random. Interestingly, the top 200 pairs in the $M_{f}-H_{f}$ network contain a higher fraction of meiotic genes than those in $M_{m}-M_{f}$ indicating that meiosis is more conserved by sex than by species. When we used human meiotic genes to evaluate conserved co-expression in two networks that contain human genes, we found similar patterns: top pairs in co-expression networks were more enriched for known meiotic genes than the randomized networks, and the $M_{m}-M_{f}-H_{f}$ network exhibited higher precision in identifying known meiotic genes than the $M_{f}-H_{f}$ network (Fig. 2B).

To determine whether conserved co-expression across species and sex can improve the identification of known meiotic genes, we created precision-coverage curves for co-expression pairs from individual studies (Fig. 2C and D). These co-expression pairs were sorted in descending order of standard $z$-score, and curves were created in 200-pair increments. Top pairs from both female mouse and female human studies failed to identify known meiotic genes. Only the top co-expression pairs from the male mouse study achieved similar precision of meiotic gene identification as those in the $M_{m}-M_{f}$ network. In meiotic gene, coverage of $13, M_{m}-M_{f}-H_{f}$ achieved $4.1 \%$ precision in identifying mouse meiotic genes while precisions of 1.2 and $0.6 \%$ were reached for networks of male mouse and female mouse respectively (Fig. 2A and C). In meiotic gene, coverage of $8, M_{f}-H_{f}$
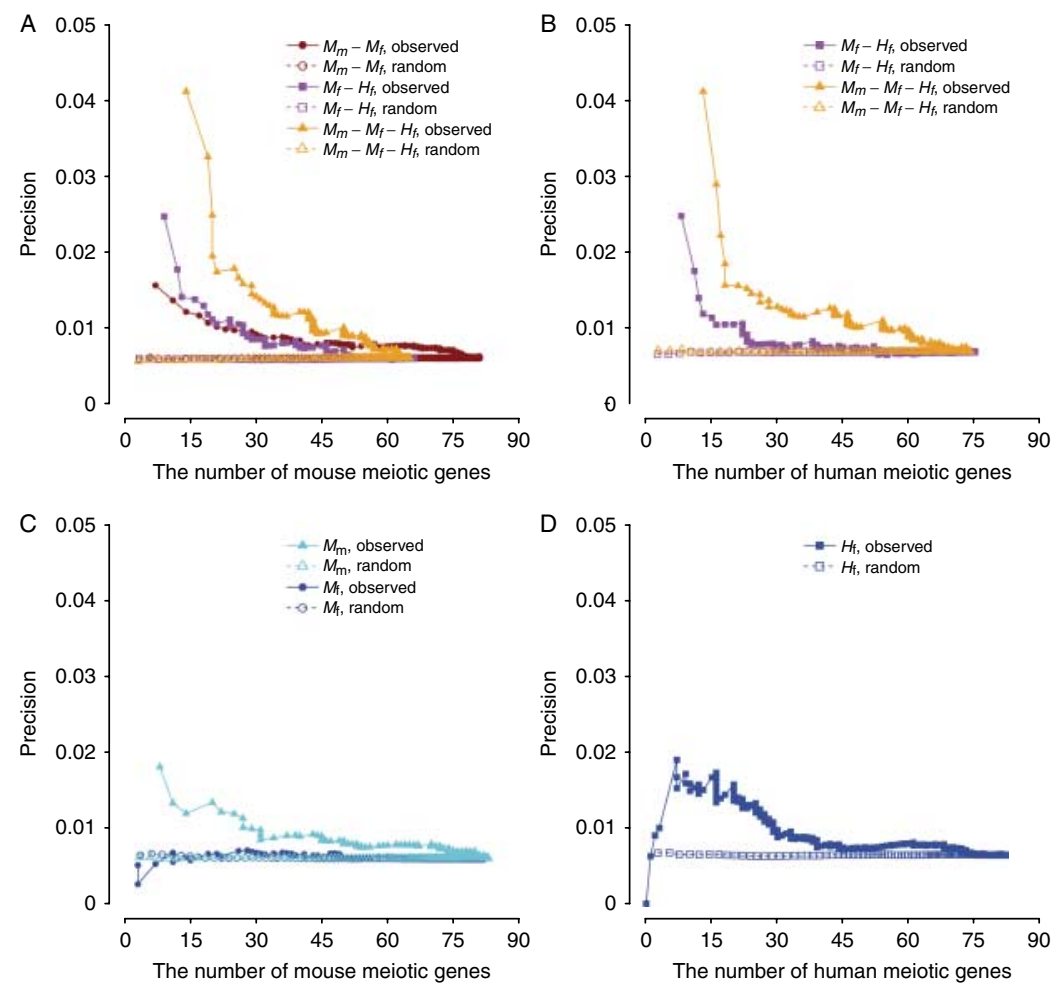

Figure 2 Co-expression across species and sex improves the identification of known meiotic genes compared with co-expression in individual studies. (A) Evaluation of conserved co-expression networks using known mouse meiotic genes. Conserved co-expression pairs were sorted in descending order of average $z$-score. To create the observed curve, precision and the number of meiotic genes were calculated from sorted pairs with an increment of 200 pairs. Precision is the fraction of meiotic genes to all genes among gene pairs. Random curves were derived from the average of 100 simulations of randomized gene pairs. (B) Evaluation of conserved co-expression networks using known human meiotic genes. The curves were similarly created as described in A. (C) Evaluation of co-expression in individual mouse studies using known mouse meiotic genes. Co-expression pairs were sorted in descending order of standard $z$-score. To create the observed curve, precision and the number of meiotic genes were calculated from sorted pairs with an increment of 200 pairs. Random curves were derived from the average of 100 simulations of randomized gene pairs. (D) Evaluation of co-expression in the human study using known human meiotic genes. The curves were similarly created as described in C. 
achieved $2.5 \%$ precision in identifying mouse meiotic genes while precision of $0.5 \%$ was reached for the female mouse network (Fig. 2A and C). The precision of $M_{m}-M_{f}$ was $1.6 \%$ in meiotic gene coverage of 6 , similar to that of male mouse study but higher than the $0.5 \%$ precision of female mouse study (Fig. 2A and C). The comparison of precision using human meiotic genes reached the similar results as those using mouse meiotic genes (Fig. 2B and D). Our goal is to develop a computational method to efficiently predict novel meiotic genes, not to identify all meiotic genes. The prediction accuracy of top-ranked gene pairs is much more interesting than the overall accuracy. Therefore, comparison of precision at a small coverage is most relevant to this goal.

The comparison between co-expression across species vs co-expression in individual species strongly supported the notion that cross-species integration of expression profiles can significantly improve the accuracy of identifying known meiotic genes and thus the accuracy of predicting novel meiotic genes. Further, cross-species integration can help us understand the meiotic differences between sex and species. We demonstrated that these results are not affected by the number of sampling gene pairs or by the use of ranked genes (Supplementary Figures 1 and 2, see section on supplementary data given at the end of this article).

Because the top 200 gene pairs in each co-expression network showed highest precision of meiotic gene identification (Fig. 2A and B), we calculated significantly enriched GO terms among mouse (Table 2) and human genes (Table 3) from them. Consistent with the precision-coverage results, we found that more meiosis-related GO terms were associated with the $M_{m}-M_{t}-$ $H_{f}$ network than with the other two networks. Enriched meiosis GO terms were similar when using mouse genes and human genes. We observed that terms describing the general meiotic process were enriched, including 'meiosis', 'male meiosis', and 'spermatogenesis'. GO terms associated with prophase were also enriched, such as 'meiotic prophase I', 'male meiosis I', 'pachytene', 'synaptonemal complex assembly', 'synapsis', 'reciprocal meiotic recombination', and 'female meiosis sister chromatid cohesion'. Finally, 'piRNA metabolic process' was a significantly enriched GO term in networks $M_{m}-M_{f}$ and $M_{m}-M_{f}-H_{f}$, which contain male expression profiles. This is consistent with the evidence that the piRNA regulatory pathway influences DNA methylation of retrotransposons in the male germ cell (Aravin et al. 2007).

We observed that the top 200 co-expression pairs in the $M_{f}-H_{f}$ network recover a higher fraction of known meiotic genes than those of $M_{m}-M_{f}$ (Fig. 2A). We investigated whether this observation is related to absolute expression levels. We identified the maximum signal intensity for each gene across prophase in each study. Then, we classified each gene as either 'highly expressed' or 'lowly expressed' based on whether the maximum signal intensity of the gene was higher or lower than the genome-wide median value. In this way, we grouped the top 200 gene pairs from the $M_{m}-M_{f}$ network into one of the three categories: both genes were highly expressed (high, high), both were lowly expressed (low, low), or one was lowly expressed while

Table 2 Significant GO terms enriched among mouse genes from the top $200 \mathrm{MH}$ gene pairs in co-expression networks ${ }^{\mathrm{a}}$.

\begin{tabular}{|c|c|c|}
\hline GO term & GO term name ${ }^{b}$ & $\begin{array}{c}\text { Hyper } \\
\text { geometric }_{P \text { value }}\end{array}$ \\
\hline \multicolumn{3}{|l|}{$M_{m}-M_{f}$} \\
\hline GO:0006596 & Polyamine biosynthetic process & 0.000 \\
\hline GO:0009267 & Cellular response to starvation & 0.001 \\
\hline GO:0007126 & Meiosis & 0.002 \\
\hline GO:0007283 & Spermatogenesis & 0.002 \\
\hline GO:0034587 & piRNA metabolic process & 0.002 \\
\hline GO:0007182 & $\begin{array}{l}\text { Common partner SMAD protein } \\
\text { phosphorylation }\end{array}$ & 0.002 \\
\hline GO:0002309 & $\begin{array}{l}\text { T cell proliferation during immune } \\
\text { response }\end{array}$ & 0.002 \\
\hline GO:0050435 & $\beta$-Amyloid metabolic process & 0.002 \\
\hline GO:0006597 & Spermine biosynthetic process & 0.002 \\
\hline GO:0044267 & Cellular protein metabolic process & 0.002 \\
\hline GO:0031047 & Gene silencing by RNA & 0.003 \\
\hline GO:0051101 & Regulation of DNA binding & 0.005 \\
\hline GO:0008295 & Spermidine biosynthetic process & 0.005 \\
\hline GO:0006857 & Oligopeptide transport & 0.008 \\
\hline \multicolumn{3}{|c|}{$M_{f}-H_{f}$} \\
\hline GO:0019478 & D-amino acid catabolic process & 0.001 \\
\hline GO:0007140 & Male meiosis & 0.002 \\
\hline GO:0001657 & Ureteric bud development & 0.002 \\
\hline GO:0007286 & Spermatid development & 0.003 \\
\hline GO:0019216 & Regulation of lipid metabolic process & 0.003 \\
\hline GO:0000239 & Pachytene & 0.005 \\
\hline GO:0009888 & Tissue development & 0.005 \\
\hline GO:0051056 & $\begin{array}{l}\text { Regulation of small GTPase-mediated } \\
\text { signal transduction }\end{array}$ & 0.005 \\
\hline GO:0030199 & Collagen fibril organization & 0.006 \\
\hline GO:0007156 & Homophilic cell adhesion & 0.007 \\
\hline GO:0007131 & Reciprocal meiotic recombination & 0.008 \\
\hline GO:0007141 & Male meiosis I & 0.008 \\
\hline GO:0019229 & Regulation of vasoconstriction & 0.008 \\
\hline \multicolumn{3}{|l|}{$M_{m}-M_{f}-H_{f}$} \\
\hline GO:0007126 & Meiosis & 0.000 \\
\hline GO:0007129 & Synapsis & 0.000 \\
\hline GO:0007130 & Synaptonemal complex assembly & 0.000 \\
\hline GO:0007140 & Male meiosis & 0.000 \\
\hline GO:0007286 & Spermatid development & 0.000 \\
\hline GO:0060395 & SMAD protein signal transduction & 0.000 \\
\hline GO:0007283 & Spermatogenesis & 0.001 \\
\hline GO:0060433 & Bronchus development & 0.001 \\
\hline GO:0009566 & Fertilization & 0.001 \\
\hline GO:0060425 & Lung morphogenesis & 0.001 \\
\hline GO:0007066 & $\begin{array}{l}\text { Female meiosis sister chromatid } \\
\text { cohesion }\end{array}$ & 0.003 \\
\hline GO:0034587 & piRNA metabolic process & 0.003 \\
\hline GO:0003014 & Renal system process & 0.003 \\
\hline GO:0000239 & Pachytene & 0.005 \\
\hline GO:0007128 & Meiotic prophase I & 0.005 \\
\hline GO:0030199 & Collagen fibril organization & 0.006 \\
\hline GO:0043046 & DNA methylation during gametogenesis & 0.008 \\
\hline GO:0007131 & Reciprocal meiotic recombination & 0.008 \\
\hline GO:0007141 & Male meiosis I & 0.008 \\
\hline
\end{tabular}

${ }^{\mathrm{a}}$ The top $\mathrm{MH}$ gene pairs are the pairs with the highest average $z$-scores in co-expression networks. ${ }^{\mathrm{b}} \mathrm{GO}$ names related to meiosis are in bold. ${ }^{\mathrm{c}} \mathrm{GO}$ term significance was defined by hypergeometric $P$ value $<0.01$. 
Table 3 Significant GO terms enriched among human genes from the top $200 \mathrm{MH}$ gene pairs in co-expression networks ${ }^{\mathrm{a}}$.

\begin{tabular}{|c|c|c|}
\hline GO term & GO term name ${ }^{b}$ & $\begin{array}{c}\text { Hyper } \\
\text { geometric }_{P \text { value }}{ }^{\mathrm{C}}\end{array}$ \\
\hline \multicolumn{3}{|l|}{$M_{f}-H_{f}$} \\
\hline GO:0007130 & Synaptonemal complex assembly & 0.000 \\
\hline GO:0008217 & Regulation of blood pressure & 0.001 \\
\hline GO:0001657 & Ureteric bud development & 0.001 \\
\hline GO:0019478 & D-amino acid catabolic process & 0.001 \\
\hline GO:0007286 & Spermatid development & 0.003 \\
\hline GO:0009566 & Fertilization & 0.003 \\
\hline GO:0010459 & Negative regulation of heart rate & 0.003 \\
\hline GO:0000239 & Pachytene & 0.005 \\
\hline GO:0035023 & $\begin{array}{l}\text { Regulation of Rho protein signal } \\
\text { transduction }\end{array}$ & 0.005 \\
\hline GO:0031100 & Organ regeneration & 0.005 \\
\hline GO:0030240 & Muscle thin filament assembly & 0.005 \\
\hline GO:0007320 & Insemination & 0.005 \\
\hline GO:0042475 & $\begin{array}{l}\text { Odontogenesis of } \\
\text { dentine-containing tooth }\end{array}$ & 0.006 \\
\hline GO:0007155 & Cell adhesion & 0.006 \\
\hline GO:0007128 & Meiotic prophase I & 0.008 \\
\hline GO:0043547 & $\begin{array}{l}\text { Positive regulation of GTPase } \\
\text { activity }\end{array}$ & 0.008 \\
\hline \multicolumn{3}{|c|}{ detivity } \\
\hline GO:0007126 & Meiosis & 0.000 \\
\hline GO:0007130 & Synaptonemal complex assembly & 0.000 \\
\hline GO:0007128 & Meiotic prophase I & 0.000 \\
\hline GO:0007286 & Spermatid development & 0.000 \\
\hline GO:0009566 & Fertilization & 0.000 \\
\hline GO:0007141 & Male meiosis I & 0.001 \\
\hline GO:0030308 & Negative regulation of cell growth & 0.002 \\
\hline GO:0007283 & Spermatogenesis & 0.003 \\
\hline GO:0007140 & Male meiosis & 0.003 \\
\hline GO:0008156 & $\begin{array}{l}\text { Negative regulation of DNA } \\
\text { replication }\end{array}$ & 0.004 \\
\hline GO:0007129 & Synapsis & 0.005 \\
\hline GO:0000239 & Pachytene & 0.005 \\
\hline GO:0045217 & Cell-cell junction maintenance & 0.005 \\
\hline GO:0030240 & Muscle thin filament assembly & 0.005 \\
\hline GO:0048268 & Clathrin coat assembly & 0.005 \\
\hline GO:0043587 & Tongue morphogenesis & 0.005 \\
\hline GO:0034587 & piRNA metabolic process & 0.008 \\
\hline GO:0001539 & Ciliary or flagellar motility & 0.008 \\
\hline GO:0007131 & Reciprocal meiotic recombination & 0.009 \\
\hline
\end{tabular}

aThe top $\mathrm{MH}$ gene pairs are the pairs with the highest average $z$-scores in co-expression networks. ${ }^{\mathrm{b}} \mathrm{GO}$ names related to meiosis are in bold. ${ }^{\mathrm{c}} \mathrm{GO}$ term significance was defined by hypergeometric $P$ value $<0.01$.

the other was highly expressed (low, high). This grouping was performed for the male mouse study and the female mouse study respectively. We found that the expression level of female mouse genes was similar to that of male mouse genes, with $70 \%(33.5 \%+26.5 \%+9.5 \%)$ of pairs in the same expression category (Fig. 3A). On the other hand, when we grouped the top 200 gene pairs from the $M_{f}-H_{f}$ network into three categories for the female mouse study and the female human study, respectively, only $52 \%(23.0 \%+21.0 \%+8.0 \%)$ of pairs showed consistent expression (Fig. 3B). This observation indicates that similar meiotic profile between female mice and female humans seen in Fig. 2A is not due to absolute expression levels. To compare genome-wide expression profile, we obtained the maximum signal intensity for each gene across prophase in each study and subsequently calculated Pearson correlation between three studies. We found that the expression profile of female mice is more similar to male mice (Pearson coefficient $=0.89$ ) than female humans (Pearson coefficient $=0.41$ ). This indicates that global expression similarity also does not contribute to the result that top pairs in the $M_{f}-H_{f}$ network recovers a higher fraction of known meiotic genes than those of $M_{m}-M_{f}$. The most likely explanation is that more meiotic genes share similar expression trend over the time course of prophase between female mouse and female human than between female mouse and male mouse.

\section{An alternative approach to identify conserved co-expression}

An alternative to quantify conserved co-expression is to use the minimum standard $z$-score across species and sex (Langfelder \& Horvath 2007). We found that our conclusions drawn from the precision-coverage curves with the average $z$-score still hold true when the minimum $z$-score is used: 1) top co-expression pairs in the observed networks are more enriched for known meiotic genes than those in the randomized networks, 2) the $M_{f}-H_{f}$ network contains a higher fraction of meiotic genes than $M_{m}-M_{f}$, and 3) top co-expression pairs in the conserved networks exhibited higher precision in identifying known meiotic genes than those in individual species networks (compare Supplementary Figure 3 (see section on supplementary data given at the end of this article) with Fig. 2C and D). Compared with the use of average $z$-score, the use of the minimum $z$-score improved the performance of $M_{m}-M_{f}$ and $M_{f}-H_{f}$ in identifying known meiotic genes but decreased the performance of $M_{m}-M_{f}-H_{f}$ (compare Supplementary Figure 3 with Fig. $2 \mathrm{~A}$ and $\mathrm{B}$ ). This is because the minimum is more vulnerable to outliers than the average. The use of the average $z$-score to identify conserved co-expression becomes more robust when the number of integrated species is increased.

\section{Characterization of conserved co-expression networks}

We quantified the functional association of conserved co-expression pairs using semantic similarity in the GO sub-ontology Biological Process (Lord et al. 2003; Fig. 4). We observed that the top co-expression pairs in all three networks exhibited closer functional association than those in randomized networks. The semantic similarity gradually declined when we proceeded the sorted list of co-expression pairs. In particular, the top co-expression pairs in $M_{m}-M_{f}-H_{f}$ showed tighter functional connections than those in the other two networks. This indicates that multiple species integration 

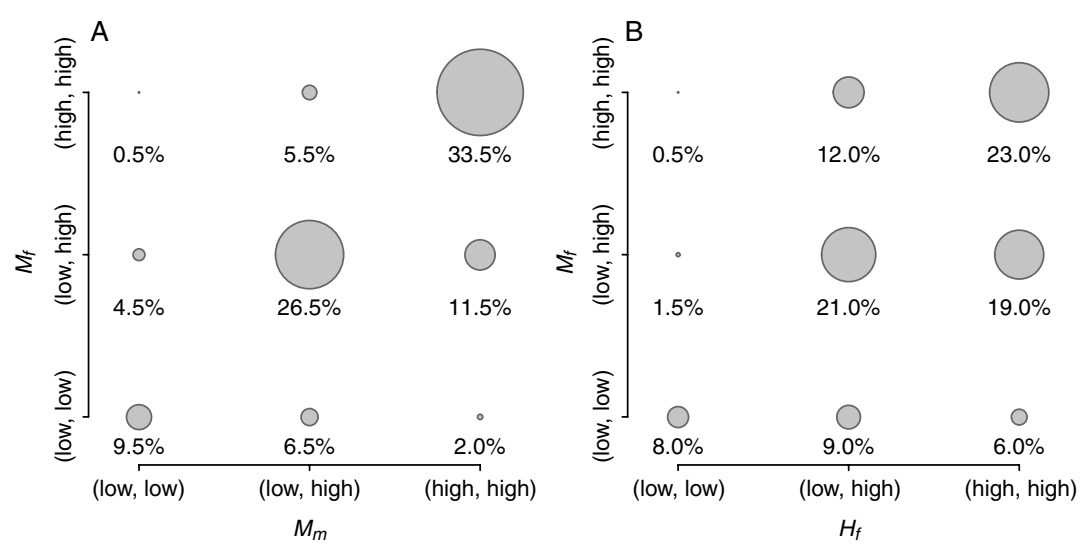

Figure 3 Expression level of the top $200 \mathrm{MH}$ gene pairs from conserved co-expression networks. Gene pairs were classified as (high, high) if expression levels of both genes were higher than the median of genome-wide levels. Gene pairs were classified as (low, low) if expression levels of both genes were lower than the median of genomewide levels. Gene pairs were classified as (low, high) if the expression level of one gene was lower than the median of genome-wide levels while the other was higher. (A) The $M_{m}-M_{f}$ network. (B) The $M_{f}-H_{f}$ network. can recover reliable predictions on gene functional associations. Results from the human GO agree with results from the mouse GO.

To examine whether top co-expression pairs exhibit physical interactions, we retrieved 23378 mouse protein-protein interactions and 227789 human protein-protein interactions from various databases (Bader et al. 2003, Salwinski et al. 2004, Stark et al. 2006, Chatr-aryamontri et al. 2007, Kerrien et al. 2007, Keshava Prasad et al. 2009). However, we observed that very few top co-expression pairs from any network overlapped with known human or mouse protein interactions. We believe that the low coverage of protein-protein interactions in mammals contributes to this result. Indeed, only one out of 6000 mouse gene pairs and one out of 600 human gene pairs would show physical interactions by chance according to the current coverage.

We tested whether genes in the co-expression networks are enriched for essential genes, i.e. those required for viability. Two genome-wide RNAi knockdown screens identified 461 human essential genes with conservation in the mouse (Schlabach et al. 2008, Silva et al. 2008). Mouse essential genes were compiled from the database of Mouse Genome Informatics (Liao \& Zhang 2008), and 1647 are conserved in the human. We found that the fraction of essential genes was slightly higher in the observed networks than in the randomized networks for both mouse and human (Fig. 5). The percentage of mouse essential genes slowly declines along the sorted list of co-expression pairs, suggesting that top co-expression pairs are more enriched with mouse essential genes (Fig. 5A). In particular, the $M_{m}-$ $M_{f}-H_{f}$ network was most enriched with mouse essential genes. This indicates that multiple species integration recovers the most conserved and essential part of cellular machinery.

Biological networks are scale free, which means that few nodes (hubs) in the network have a large number of directly connecting neighbors and a large number of nodes have few neighbors (Barabasi \& Oltvai 2004). Thus, under a scale-free architecture, the degree distribution decreases exponentially with the degree, where degree is the number of direct neighbors for a given node. We found that all three conserved co-expression networks displayed scale-free properties, and genes in $M_{m}-M_{f}-H_{f}$ and $M_{f}-H_{f}$ were more connected than those in $M_{m}-M_{f}$ (Fig. 6A). This inhomogeneous connectivity indicates that a small number of genes show co-expression with many other genes while a large number of genes exhibit co-expression with very few genes. Such architecture makes the network robust against random removal of a large fraction of genes. The clustering coefficient measures how well the neighbors of a node are connected. A value of 1 indicates that all neighbors of the node are
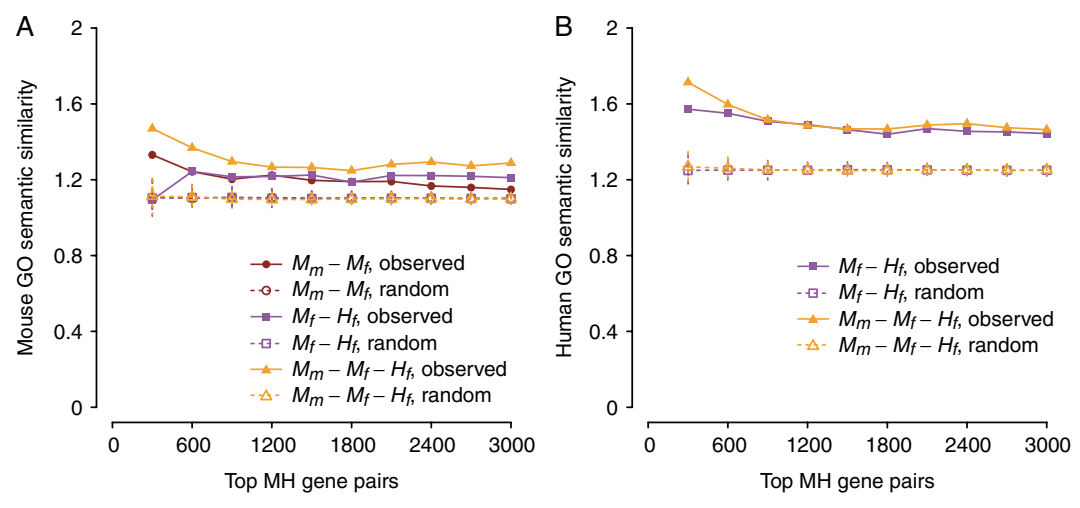

Figure $4 \mathrm{GO}$ semantic similarity of top $\mathrm{MH}$ gene pairs in conserved co-expression networks. Semantic similarity was calculated using GO sub-ontology Biological Process. The randomized curves were derived from the average of 100 simulations of randomized gene pairs. (A) Mouse GO semantic similarity. (B) Human GO semantic similarity. 


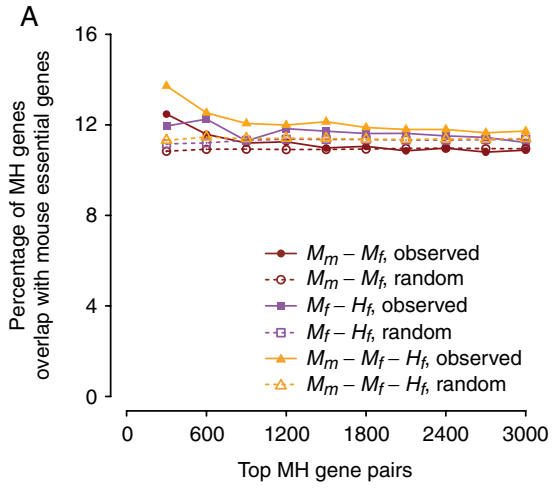

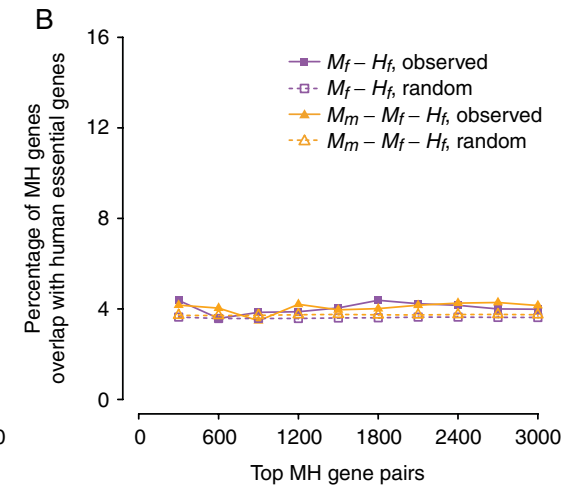

Figure 5 The enrichment of essential genes among top $\mathrm{MH}$ gene pairs from conserved co-expression networks. The randomized curves were derived from the average of 100 simulations of randomized gene pairs. (A) Mouse essential genes. (B) Human essential genes. connected with each other; a value of 0 indicates no connections in the neighborhood. The distribution of clustering coefficients displayed similar patterns for all three networks (Fig. 6B). The majority of genes had coefficients of $0 ; \sim 10 \%$ of genes had fully connected neighborhood. Overall, the global network properties are highly comparable among three conserved coexpression networks.

\section{Prediction of novel meiotic genes from conserved co-expression networks}

Conserved co-expression networks identified genes displaying similar expression across species and sex during meiotic prophase. Hence, a co-expression network can serve as a topological map to indicate potential functional connections among genes. To predict novel meiotic genes based on conserved co-expression, we focused on the top 200 pairs in three networks, $M_{m}-M_{f}$, $M_{f}-H_{f}$ and $M_{m}-M_{f}-H_{f}$. The rationale is that they are most enriched with known meiotic genes (Fig. 2A and B) and exhibit the closest functional associations (Fig. 4). The top 200 gene pairs for each network are listed in Supplementary Table 1 (see section on supplementary data given at the end of this article) while the gene pairs that appeared in more than one network are summarized in Table 4.
Gene clusters containing known mouse or human meiotic genes were isolated from the networks for display (Fig. 7). We used mouse gene names to label $\mathrm{MH}$ genes because mouse is present in every network. Four functional categories of known meiotic genes were identified from the networks: components of the synaptonemal complex (Sycp2, Sycp3, Tex11, and Tex15), meiosis-specific cohesins (Smc1b and Stag3), meiotic recombination machinery (Dmc1, Msh4, and Trip13), and genes involved in the piRNA pathway (Piwil2, Tdrd1, and Mael). We focused on candidate meiotic genes that exhibited direct co-expression links with known meiotic genes. Some of these candidates are supported by published experiments for their functions in testis and ovary development, yet others are entirely new with no previous associations with meiosis. For example, many human disease genes, including tumorsuppressor genes, displayed direct co-expression links with known meiotic genes.

The synaptonemal complex consists of two lateral elements and the transverse filament in the middle. This structure results from the pairing of two homologous chromosomes and allows for recombination between the homologous chromosomes. SYCP2 and SYCP3 are components of the lateral elements. The co-expression link between Sycp2 and Tex11 in the $M_{f}-H_{f}$ network is well supported by the observed physical interaction between the encoded proteins (Yang et al. 2008b). Sycp2
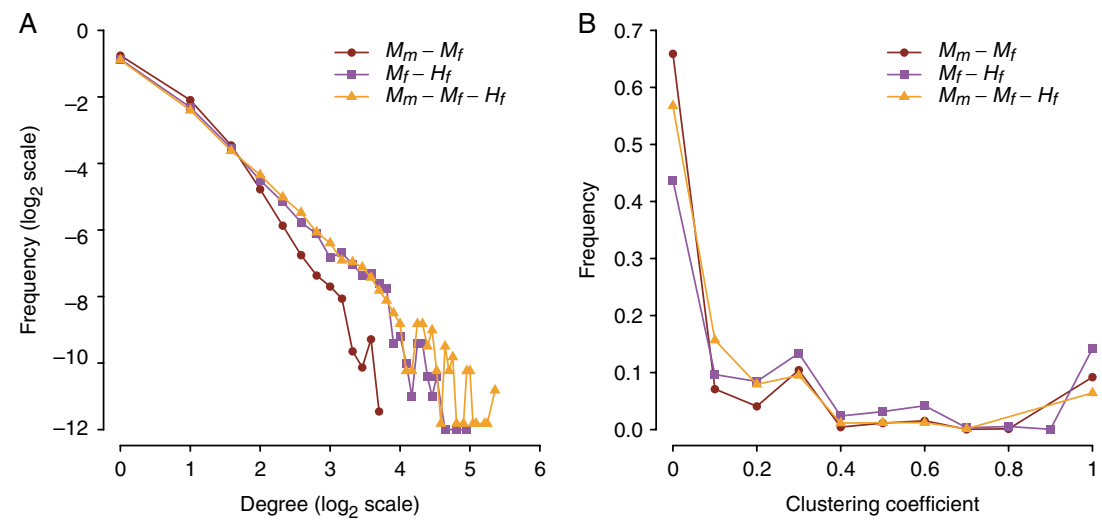

Figure 6 Network properties of conserved co-expressions networks. Results were derived from the top $5000 \mathrm{MH}$ gene pairs; results were similar by including more or fewer numbers of gene pairs. (A) The degree distribution. Degree is the number of direct neighbors a gene has. (B) The distribution of clustering coefficients. Clustering coefficient measures the neighborhood connectivity around a gene. 
Table 4 The top $200 \mathrm{MH}$ gene pairs common to at least two out of three co-expression networks ${ }^{\mathrm{a}}$.

\begin{tabular}{|c|c|c|c|}
\hline $\begin{array}{l}\text { MH pair using mouse } \\
\text { gene symbols }\end{array}$ & $M_{m}-M_{f}$ & $M_{f}-H_{f}$ & $M_{m}-M_{f}-H_{f}$ \\
\hline Lpp-Postn & + & + & + \\
\hline Rg9mtd2-Zfp238 & + & + & + \\
\hline Trim23-Zhx1 & + & + & + \\
\hline Ikbkap-Nans & + & + & + \\
\hline Anxa9-Sipa1/2 & + & + & + \\
\hline Ncam2-Ndufs5 & + & + & + \\
\hline Dnaja4-Serinc3 & + & + & + \\
\hline Adamts2-Col6a3 & + & + & + \\
\hline $\mathrm{Ccd} 744 \mathrm{a}-\mathrm{Fb} \times 18$ & + & + & \\
\hline Birc2-Mrp/11 & + & + & \\
\hline A630055G03Rik-Zc3h12c & + & + & \\
\hline Rab21-Scly & + & & + \\
\hline 1810074P20Rik-Mtmr6 & + & & + \\
\hline Dmc1-Smc1b & + & & + \\
\hline Clock-Rabgap1l & + & & + \\
\hline 1700021F05Rik-Hyal1 & + & & + \\
\hline 6030405A18Rik-Pard3 & + & & + \\
\hline Nlgn2-Rsad2 & + & & + \\
\hline Agtr2-Fbxl7 & + & & + \\
\hline Ghitm-Hoxс13 & + & & + \\
\hline Dyx1c1-Lrrc50 & + & & + \\
\hline Pml-Rgs11 & + & & + \\
\hline Cgn-Eef2 & + & & + \\
\hline Pign-Prei4 & + & & + \\
\hline Armcx6-Lox & + & & + \\
\hline 4930473A06Rik-Smc1b & + & & + \\
\hline Stk22s1-Wnk4 & + & & + \\
\hline Alg8-Car5a & + & & + \\
\hline Cnot6-Smad6 & + & & + \\
\hline$K d s r-X r n 1$ & + & & + \\
\hline Eif2ak4-Pcdhb22 & + & & + \\
\hline 4932438A13Rik-Trim23 & + & & + \\
\hline Dnahc8-Tcte3 & + & & + \\
\hline Pogz-Rcbtb1 & + & & + \\
\hline 1600027N09Rik-Pex7 & + & & + \\
\hline Dnahc8-Lypd4 & + & & + \\
\hline Stk33-Zpbp & + & & + \\
\hline Fbxo36-Sccpdh & + & & + \\
\hline Apba3-Fut11 & + & & + \\
\hline Eif3eip-Nans & + & & + \\
\hline Glyat-Ren2 & & + & + \\
\hline 4921507P07Rik-Rad17 & & + & + \\
\hline Ccdc93-Phlpp & & + & + \\
\hline Spaca1-Tex12 & & + & + \\
\hline Cd248-Cyyr1 & & + & + \\
\hline 1700123l01Rik-Smc1b & & + & + \\
\hline Oip5-Pik3r3 & & + & + \\
\hline Dmap1-Dnase1 & & + & + \\
\hline Adad1-Hormad2 & & + & + \\
\hline Afp-Cldn2 & & + & + \\
\hline Rps6ka3-Trip13 & & + & + \\
\hline Piwil2-Zfp473 & & + & + \\
\hline Lrrc51-Slc25a19 & & + & + \\
\hline Smtn|2-Zfp467 & & + & + \\
\hline Glis2-Rgs3 & & + & + \\
\hline Fcgrt-Mpz & & + & + \\
\hline Bbs4-Steap1 & & + & + \\
\hline Eif1b-Tmem135 & & + & + \\
\hline Stc1-Trps1 & & + & + \\
\hline Dgat2-Rab28 & & + & + \\
\hline Ints6-Smc1b & & + & + \\
\hline Dmrtc2-Hormad2 & & + & + \\
\hline Bmp4-Tcf21 & & + & + \\
\hline Ppp2r1a-Spr & & + & + \\
\hline Gjb6-Pck1 & & + & + \\
\hline 1700123I01Rik-Ints6 & & + & + \\
\hline
\end{tabular}

Table 4 Continued.

\begin{tabular}{|c|c|c|c|}
\hline $\begin{array}{l}\text { MH pair using mouse } \\
\text { gene symbols }\end{array}$ & $M_{m}-M_{f}$ & $M_{f}-H_{f}$ & $M_{m}-M_{f}-H_{f}$ \\
\hline Ch/1-Rg/1 & & + & + \\
\hline Ccdc21-Sepsecs & & + & + \\
\hline Gabarap/2-Lrrfip2 & & + & + \\
\hline Ogn-Sdpr & & + & + \\
\hline Garnl1-Taf12 & & + & + \\
\hline O610010D2ORik-Bbox1 & & + & + \\
\hline Acta1-Actc1 & & + & + \\
\hline Tex15-Ugt8a & & + & + \\
\hline Acta1-Mylpf & & + & + \\
\hline Armcx3-Rbms1 & & + & + \\
\hline Smtn/2-Tgfb1i1 & & + & + \\
\hline Dmc1-Ints6 & & + & + \\
\hline Nrgn-Setd1a & & + & + \\
\hline Myl1-Vg/l2 & & + & + \\
\hline 2310065K24Rik-Dnase1 & & + & + \\
\hline 4931406P16Rik-Mfsd11 & & + & + \\
\hline 1700123l01Rik-Dmc1 & & + & + \\
\hline Acta1-Casq2 & & + & + \\
\hline
\end{tabular}

${ }^{\mathrm{a}}$ The top $\mathrm{MH}$ gene pairs are the pairs with the highest average $z$-scores in co-expression networks.

is connected with several non-meiotic genes in addition to Sycp3 in the $M_{m}-M_{f}-H_{f}$ network, including Hspa4l, Hsf2bp, Trf, and Hormad2. Tex11 and Tex15 are required for chromosomal synapsis and recombination (Yang et al. 2008a, 2008b). Tex11 is connected to Hsp4l in $M_{f}-H_{f}$ and to Krit1 in $M_{m}-M_{f}-H_{f}$, while Tex15 is connected to Ugt8a in both networks. Among the candidate meiotic genes, Hspa4l and Hsf2bp are heatshock proteins predominantly expressed in the testis (Yoshima et al. 1998, Held et al. 2006). In particular, Hspa4l-deficient mice display reduced male fertility. These findings are consistent with our prediction that Hspa4l and Hsf2bp might participate in synapsis and recombination. Trf also exhibits expression in the testis, and its protein level correlates with sperm yield in several mammalian species (Lecureuil et al. 2007). Hormad2 was shown to associate with unsynapsed chromosome axes during meiotic prophase (Wojtasz et al. 2009), which supports our prediction for the role of Hormad2 in the formation of the synaptonemal complex. Finally, Krit1, containing four ankyrin repeats, is expressed in the testis, and mutations in the gene result in cerebral cavernous malformations (Kehrer-Sawatzki et al. 2002).

Meiosis-specific cohesion proteins are closely aligned with SYCP2 and SYCP3 to form the lateral elements. They play a key role in synapsis, recombination, and chromosome segregation. We observed that cohesin Smc1b has a co-expression link with Dmc1 in $M_{m}-M_{f}$ and $M_{m}-M_{f}-H_{f}$, suggesting concordant expression of sister chromatid cohesion and early homologous recombination events during meiotic prophase. Smc1b is also connected with non-meiotic genes Ints6 and Krit1 in $M_{f}-H_{f}$ and Ints6 and Atf7ip2 in $M_{m}-M_{f}-H_{f}$. Particularly, Smc1b, Dmc1, Ints6, and Atf7ip2 form a four-node 

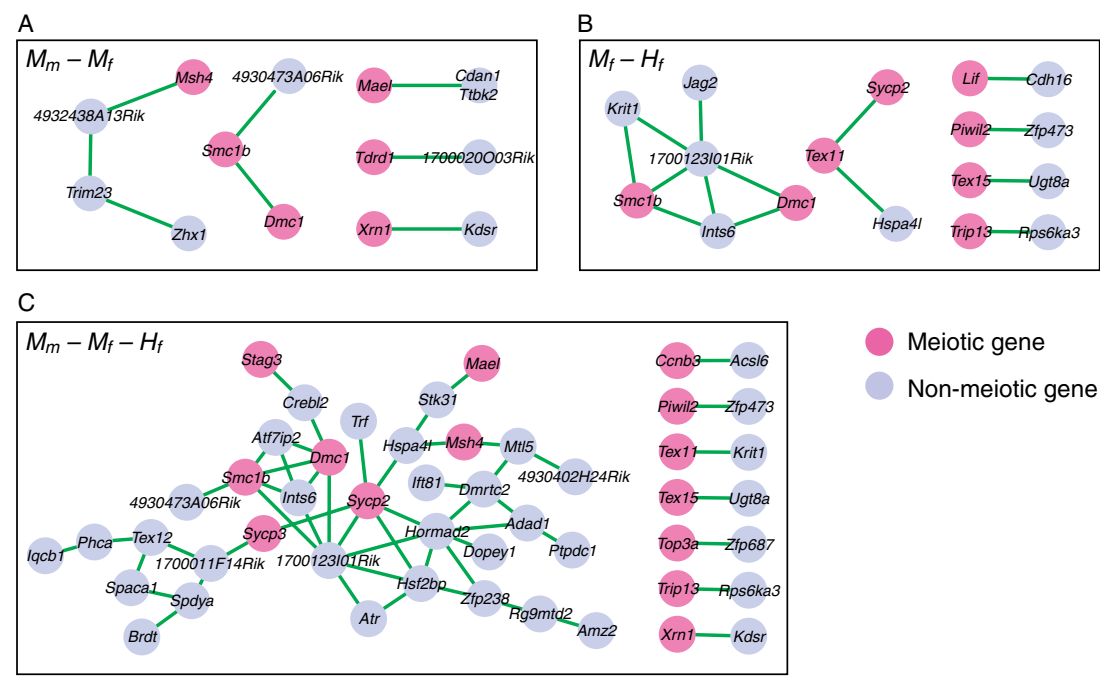

clique (each node has a connection to each of the others) in $M_{m}-M_{f}-H_{f}$, suggesting related functions of these genes. Additionally, a couple of putative uncharacterized genes are directly linked to $S m c 1 b$. In contrast to the high connectivity of Smc1b, Stag3 only connects to the non-meiotic gene Creb/2 in $M_{m}-M_{f}-H_{f}$. Among the candidate meiotic genes that are linked to cohesins, Ints6 and Creb/2 are tumor suppressor genes and participate in cell cycle regulation (Thomson et al. 2008, Filleur et al. 2009). Atf7ip2 is expressed both in the embryonic gonad and continuously in the testis from newborn to adult, suggesting a potential role in transcription modulation during gonad development (Cai et al. 2006).

Meiotic recombination occurs in the context of the synaptonemal complex. The process is initiated by double-strand breaks, followed by strand invasion, and the formation of double Holliday junctions. Resolution of Holliday junctions results in chromosomal crossovers. Dmc1, which encodes a strand-invasion protein, connects with cohesin Smc1b in all three networks. MSH4 is a mismatch repair protein, and Msh4 links to $\mathrm{Hsp} 4 \mathrm{I}$ and $\mathrm{Mtl} / 5$ in the $M_{m}-M_{f}-H_{f}$ network. Mtl5 encodes a metallothionein-like protein, which is expressed in both male and female meiotic prophase (Olesen et al. 2004). Trip13 is required for meiotic recombination (Li \& Schimenti 2007, Roig et al. 2010) and links with Rps6ka3 in both $M_{f}-H_{f}$ and $M_{m}-M_{f}-H_{f}$. The role of Rps6ka3 in meiosis has never been described, but mutations in this gene, which encodes a growth factor-regulated serine-threonine protein kinase, have been associated with CoffinLowry syndrome, an X-linked disorder characterized by retardation and skeletal deformations (Delaunoy et al. 2001).

Interestingly, several genes involved in piRNA metabolism were identified from the conserved co-expression networks. Three Miwi genes, Piwil1, Piwil2, and Piwil4,
Meiotic gene

Non-meiotic gene

Figure 7 The conserved co-expression networks. Connecting the top $200 \mathrm{MH}$ gene pairs formed the networks. Clusters containing known mouse or human meiotic genes were displayed in the figure. Genes were labeled with mouse gene symbols. (A) The $M_{m}-M_{f}$ network. (B) The $M_{f}-H_{f}$ network. (C) The $M_{m}-M_{f}-$ network. are mainly expressed in the male germ cell; each is required for spermatogenesis (Deng \& Lin 2002, Kuramochi-Miyagawa et al. 2004, Carmell et al. 2007). The Miwi-piRNA complex causes retrotransposon silencing via DNA methylation and thus prevents DNA damage in the germ cell. We found that $Z f p 473$ is linked to Piwil2 in both $M_{f}-H_{f}$ and $M_{m}-M_{f}-H_{f}$. Piwil2 is the only Miwi expressed in the prenatal oocyte (Watanabe et al. 2008). This is consistent with the appearance of Piwil2 in the female-containing networks. The link between Piwil2 and Zfp473 suggests that Zfp473 might function as a germ cell-specific transcription factor during meiosis. MAEL forms a complex with piRNAs and Miwi proteins and plays a central role during spermatogenesis by repressing transposable elements (Soper et al. 2008). Mael connects with Cdan1 and Ttbk2 in $M_{m}-M_{f}$ and with Stk31 in $M_{m}-M_{f}-H_{f}$. Mutations in Cdan 1 cause congenital dyserythropoietic anemia type I, while mutations in Ttbk2 lead to the neurodegenerative disease spinocerebellar ataxia type 11 (Dgany et al. 2002, Houlden et al. 2007). STK31 is a serine-threonine kinase, which displays testis-specific expression as well as high expression in colorectal cancer samples (Yokoe et al. 2008). Meiotic functions of these three genes have never been described earlier.

\section{Discussion}

Meiosis is an essential developmental program that determines the quality and quantity of the next generation. Any error during this process can lead to infertility, miscarriages, or birth defects. Recently, considerable interest has focused on the derivation of functional gametes from embryonic stem cells or induced pluripotent stem cells in vitro (Geijsen et al. 2004, Nayernia et al. 2006). However, the development of such technologies requires a thorough 
understanding of a highly complex series of interrelated pathways leading to germ cell entry and progress through meiosis. Presently, such information is lacking: only a very limited number of meiotic genes have been characterized, and even less is known about the interactions between meiotic genes. A better understanding of the meiotic program will improve our ability to generate therapeutic strategies to overcome meiotic defects.

Microarray profiles of testis and ovary simultaneously capture expression of thousands of genes during meiosis. However, gonad samples contain mixed germ cells and somatic cells, and not all germ cells undergo meiosis in a synchronized fashion. Further, due to the difficulties of retrieving gonads, only limited time points have been covered in expression studies. Therefore, the quality of expression profiles of mammalian gonads is inferior to that of model organisms such as yeast. Under such circumstances, bioinformatics approaches become necessary to remove noise and decode germ cell signals from gonad microarray profiles.

We used the Pearson correlation and a resulting $z$-score to identify conserved gene pairs displaying co-expression in male and female gonads across mouse and human. Further, we developed an efficient 'divide and conquer' algorithm to implement our method on a standard desktop computer. Our conserved co-expression networks provide a comprehensive understanding of real and potential interactions between genes in mammalian meiotic prophase. This approach significantly improved the identification of known meiotic genes compared with examining individual expression profiles. More importantly, this approach is quantitative, i.e. a score is assigned to each co-expression link between two genes in a network, thus allowing us to prioritize candidate meiotic genes and interactions for targeted experiments. Additionally, our study offers a better understanding of meiotic differences between sex and species, suggesting that meiosis is more conserved by sex than by species. Although sexual dimorphism in meiosis is well known, including the differences in timing, outcome, and checkpoint control (Morelli \& Cohen 2005, Bowles \& Koopman 2007, Kimble \& Page 2007, Hunt \& Hassold 2008), our genome-wide unbiased approach provides direct evidence on the number of conserved meiotic genes to support sexual dimorphism. Further, our approach allows direct comparison between cross-sex conservation and crossspecies conservation. The difference between $M_{f}-H_{f}$ and $M_{m}-M_{f}$ in identifying known meiotic genes is relatively small, which we believe is partly due to the small number of known meiotic genes that are conserved between human and mouse ( $\sim 80$ genes, indicated as the maximal $x$-axis value in Fig. 2). However, our conclusion that meiosis is more conserved by sex than by species still holds even when we created precision-coverage curves by sampling every
100 gene pairs (Supplementary Figure 1), by sampling every 200 genes from ranked pairs (Supplementary Figure 2), or by an alternative method of using the minimum to define conserved networks (Supplementary Figure 3). These new approaches indicate that the meiosis conservation by sex is indeed a robust phenomenon.

The known meiotic genes identified from our coexpression networks encode for synaptonemal complex components, meiosis-specific cohesins, recombination proteins, and piRNA complex components. We focused on investigating candidate genes that display direct links with known meiotic genes. Some candidates are supported by published experiments, in which expression was detected in the testis and the ovary. However, other candidates are human disease genes, including tumor suppressors, with no previous associations with meiosis. Interestingly, we know that several genes initially linked to cancer, such as Mlh1 and Pms2, were later identified as meiotic genes because the knockout mice exhibited severe meiotic defects and infertility (Baker et al. 1995, 1996). The dual roles of a gene can be explained by shared DNA repair mechanisms. Tumor formation in somatic cells may result from failed DNA damage repair and meiotic recombination in germ cells evolved from somatic DNA repair mechanisms. Therefore, some genes may perform related but not necessarily identical functions in somatic and germ cells; mutations in these genes may cause both tumors and meiotic defects. The candidate meiotic genes identified from our study represent valuable targets for further functional characterization.

We focused on microarray data of testis and ovary tissues from human and mouse. Although it is possible to obtain purified germ cell populations in the male using physical separation methods, it is extremely difficult to isolate germ cells in the female due to the size of the fetal ovary and the source of human tissues. Consequently, microarray data on purified meiotic populations are only available in the male (Shima et al. 2004, Chalmel et al. 2007), which makes cross-sex inference impossible. One study used isolated male germ cells to characterize conserved expression in human and rodents (Chalmel et al. 2007). A clustering method identified 217 potential meiotic genes showing similar expression in male mouse and rat. The precision of identifying known mouse meiotic genes from the 217 genes is $3.2 \%$, comparable to the performance of top 200 gene pairs in our three networks. The advantage of our approach is the capability of prioritizing candidate genes based on the quantitative co-expression links with known meiotic genes. Our study focused on identifying conserved meiotic genes. The limitation of the approach is the possibility of missing sex-specific and species-specific meiotic genes. However, the knowledge of mammalian meiosis is extremely limited, and functional characterization of meiotic genes using animal models is 
expensive and time-consuming. Therefore, the current priority is to improve the prediction accuracy on candidate meiotic genes. Our approach fits well with this priority.

In summary, our study identified conserved meiotic programs and predicted novel meiotic genes. This information will enable us to better understand abnormal meiotic processes. The diversity and amount of genomic data will continue to grow, and our approach provides a flexible means by which future data can be integrated to generate new knowledge on mammalian meiosis.

\section{Materials and Methods}

\section{Genes conserved between mouse and human}

Orthologous clusters of human and mouse genes were downloaded from the database InParanoid (Ostlund et al. 2010). InParanoid provides a robust method for detecting orthologous relationships between two species because multiple alignments and phylogenetic trees - error-prone steps in classical ortholog detection - are bypassed. Ortholog clusters in InParanoid are seeded with orthologs based on reciprocal best match between two species, after which inparalogs are added. Only seed orthologs, the most confident genes conserved between mouse and human, were kept for our analysis. We termed these conserved genes MHs. A total of $16376 \mathrm{MHs}$ were identified, covering $\sim 77 \%$ of human genes and $71 \%$ of mouse genes. Most MHs contain a single gene from each species, and each gene was assigned to only one $\mathrm{MH}$ (Table 1 ).

\section{Gene co-expression in meiotic prophase}

To investigate gene co-expression during mammalian meiotic prophase, we selected three time series microarray studies on mouse postnatal testis (GSE12769), mouse embryonic ovary (GSE6916), and human fetal ovary (GSE15431; Shima et al. 2004, Small et al. 2005, Houmard et al. 2009). Mouse Genome 4302.0 Array (Affymetrix, Santa Clara, CA, USA) was used for both male and female mouse studies; human Genome U133A Plus 2.0 Array (Affymetrix) was used for the female human study. Time series microarray data are currently unavailable for the human male due to the difficulties of retrieving juvenile testis samples. Only time points within meiotic prophase were included in our analysis, which are 6,8 , 10 , and 14 days post partum for the male mouse; $11.5,12.5$, 14.5 , and 16.5 days post coitum for the female mouse; and 9.1, $9.6,11,12,12.9,13.6,13.9,14.4,16.1,16.4,16.9,17.1$, and 18.1 weeks of gestation for the female human. Microarray data were normalized as described in the original studies. Gene signal intensities were obtained by averaging signals of corresponding probes. The maximum signal intensity of each gene was identified across prophase in each microarray study. The top $90 \%$ of highly expressed genes based on the maximum signal intensity were kept for co-expression analysis. This criterion prevents the introduction of very lowly expressed genes into the gene co-expression network, as their signals are often dominated by noise.
We calculated the Pearson correlation coefficient $r_{x y}$ to assess co-expression of each $\mathrm{MH}$ gene pair across prophase in each microarray study separately:

$r_{x y}=\sum_{i=1}^{n}\left(x_{i}-\bar{x}\right)\left(y_{i}-\bar{y}\right) /(n-1) S_{x} S_{y}$,

where $x$ and $y$ are expression data vector of length $n$ for two genes, $\bar{x}$ and $\bar{y}$ are means, and $S_{x}$ and $S_{y}$ are S.D. If an $\mathrm{MH}$ contains more than one gene in a species, Pearson correlations for $\mathrm{MH}$ gene pairs were computed by averaging multiple gene pairs' Pearson correlations. The correlation coefficients $r_{x y}$ were Fisher's $z^{\prime}$-transformed, $z^{\prime}=0.5 \times\left(\ln \left(1+r_{x y}\right)-\ln \left(1-r_{x y}\right)\right)$, to ensure normal distribution of correlation coefficients in each microarray study. The Fisher's $z^{\prime}$ were further converted into standard $z$-scores, $z=\left(z^{\prime}-\bar{z}^{\prime}\right) / s_{z^{\prime}}$, where $\bar{z}^{\prime}$ is the mean and $s_{z^{\prime}}$ is the S.D. over all MH pairs for each microarray study. This step ensures comparable standard normal distribution across species and sex.

\section{Conserved co-expression networks of mammalian meiotic prophase}

To identify conserved co-expression gene pairs, we averaged standard $z$-scores across species and sex to obtain the average $z$-score for each $\mathrm{MH}$ gene pair. Obtaining average $z$-scores across species and sex demands a large computer memory because 100000000 pairs need to be considered from each microarray study. We designed an efficient 'divide and conquer' algorithm to accomplish this calculation on a standard desktop computer. A divide and conquer algorithm works by breaking down a problem into a number of subproblems until they become simple enough to be solved directly. The solutions to the sub-problems are then combined to give a solution to the original problem. Using the algorithm we designed, the calculation of the two-species networks $\left(M_{m}-M_{f}\right.$ and $\left.M_{f}-H_{f}\right)$ was completed in $1 \mathrm{~h}$, while the calculation of the three-species network $\left(M_{m}-M_{f}-H_{f}\right)$ was completed in $3 \mathrm{~h}$ (iMac with $4 \mathrm{~GB}$ memory and $3.06 \mathrm{GHz}$ Intel Core 2 Duo processor). The pseudo-code for the algorithm is provided below.

Input:

List 1: all possible $\mathrm{MH}$ gene pairs $(16376 \mathrm{MH}$ genes $\times 16375 \mathrm{MH}$ genes/2)

List 2: $\mathrm{MH}$ gene pairs with male mouse $z$-scores

List 3: $\mathrm{MH}$ gene pairs with female mouse $z$-scores

List 4: MH gene pairs with female human $z$-scores.

Divide List 1 into sub-lists so that the computer memory can store one sub-list

For each sub-list

For each $\mathrm{MH}$ gene pair in the sub-list

Obtain standard $z$-scores of the pair from List 2 to 4

Obtain the average $z$-score of the pair

Delete the pair from List 2 to 4

Output:

A list of $\mathrm{MH}$ gene pairs with average $z$-scores. 


\section{Randomization of co-expression networks}

An observed network was obtained by sorting $\mathrm{MH}$ gene pairs in descending order of average $z$-score. Randomizing the order of $\mathrm{MH}$ pairs generated a randomized network. This process was repeated 100 times to produce 100 randomized networks. Results from the average over 100 randomizations were described.

\section{GO term enrichment}

We used significantly enriched GO terms to describe common functions of a gene set. To determine whether a GO term is enriched in a gene set, we calculated the $P$ value from a hypergeometric distribution:

$P(X \geq k)=\sum_{X=k}^{\min (m, n)} \frac{\left(\begin{array}{l}m \\ k\end{array}\right)\left(\begin{array}{c}N-m \\ n-k\end{array}\right)}{\left(\begin{array}{l}N \\ n\end{array}\right)}$.

In this equation, $N$ is the total number of genes in a co-expression network, $m$ is the number of genes in the network annotated by the GO term, $n$ is the number of genes in the set (for example, genes in top $200 \mathrm{MH}$ gene pairs), and $k$ is the number of genes in the set and annotated by the GO term.

\section{Semantic similarity}

The calculation of semantic similarity for gene pairs was described in detail by Lord et al. (2003). Briefly, each GO term in the GO hierarchy is assigned a probability, corresponding to the chance of a concept occurring on this term or its children. Thus, the probability increases as we move to the top of the GO hierarchy, where the probability is equal to 1 . A pair of genes may be co-annotated by more than one GO term. To calculate the semantic similarity for a pair of genes, the shared GO term with the minimal probability will be identified. The similarity score is defined as the negative log10 of the minimal probability. Because each gene pair is associated with a similarity score, an averaged semantic similarity can be calculated for a group of gene pairs to quantify their functional association.

\section{Supplementary data}

This is linked to the online version of the paper at http://dx.doi. org/10.1530/REP-11-0260.

\section{Declaration of interest}

The authors declare that there is no conflict of interest that could be perceived as prejudicing the impartiality of the research reported.

\section{Funding}

This work was supported by the March of Dimes Basil O'Connor Starter Scholar Research Award (grant number \#5-FY10-485) and Washington State University Start-up funds to P Ye.

\section{Acknowledgements}

The authors would like to thank Nairanjana Dasgupta for helpful discussions.

\section{References}

Aravin AA, Sachidanandam R, Girard A, Fejes-Toth K \& Hannon GJ 2007 Developmentally regulated piRNA clusters implicate MILI in transposon control. Science 316 744-747. (doi:10.1126/science.1142612)

Bader GD, Betel D \& Hogue CW 2003 BIND: the biomolecular interaction network database. Nucleic Acids Research 31 248-250. (doi:10.1093/ nar/gkg056)

Baker SM, Bronner CE, Zhang L, Plug AW, Robatzek M, Warren G, Elliott EA, Yu J, Ashley T, Arnheim N et al. 1995 Male mice defective in the DNA mismatch repair gene PMS2 exhibit abnormal chromosome synapsis in meiosis. Cell 82 309-319. (doi:10.1016/0092-8674(95)90318-6)

Baker SM, Plug AW, Prolla TA, Bronner CE, Harris AC, Yao X, Christie DM, Monell C, Arnheim N, Bradley A et al. 1996 Involvement of mouse Mlh1 in DNA mismatch repair and meiotic crossing over. Nature Genetics 13 336-342. (doi:10.1038/ng0796-336)

Barabasi AL \& Oltvai ZN 2004 Network biology: understanding the cell's functional organization. Nature Reviews. Genetics 5 101-113. (doi:10. 1038/nrg1272)

Bowles J \& Koopman P 2007 Retinoic acid, meiosis and germ cell fate in mammals. Development 134 3401-3411. (doi:10.1242/dev.001107)

Cai H, Hu J, Song P \& Gong W 2006 PSM2, a novel protein similar to MCAF2, is involved in the mouse embryonic and adult male gonad development. Molecular Biology Reports 33 159-166. (doi:10.1007/ s11033-006-0001-z)

Carmell MA, Girard A, van de Kant HJ, Bourc'his D, Bestor TH, de Rooij DG \& Hannon GJ 2007 MIWI2 is essential for spermatogenesis and repression of transposons in the mouse male germline. Developmental Cell 12 503-514. (doi:10.1016/j.devcel.2007.03.001)

Chalmel F, Rolland AD, Niederhauser-Wiederkehr C, Chung SS, Demougin P, Gattiker A, Moore J, Patard JJ, Wolgemuth DJ, Jegou B et al. 2007 The conserved transcriptome in human and rodent male gametogenesis. PNAS 104 8346-8351. (doi:10.1073/pnas.0701883104)

Chatr-aryamontri A, Ceol A, Palazzi LM, Nardelli G, Schneider MV, Castagnoli L \& Cesareni G 2007 MINT: the molecular interaction database. Nucleic Acids Research 35 D572-D574. (doi:10.1093/nar/gk1950)

Delaunoy J, Abidi F, Zeniou M, Jacquot S, Merienne K, Pannetier S, Schmitt M, Schwartz C \& Hanauer A 2001 Mutations in the X-linked RSK2 gene (RPS6KA3) in patients with Coffin-Lowry syndrome. Human Mutation 17 103-116. (doi:10.1002/1098-1004(200102) 17:2<103::AID-HUMU2>3.0.CO;2-N)

Deng W \& Lin H 2002 miwi, a murine homolog of piwi, encodes a cytoplasmic protein essential for spermatogenesis. Developmental Cell 2 819-830. (doi:10.1016/S1534-5807(02)00165-X)

Dgany O, Avidan N, Delaunay J, Krasnov T, Shalmon L, Shalev H, EidelitzMarkus T, Kapelushnik J, Cattan D, Pariente A et al. 2002 Congenital dyserythropoietic anemia type I is caused by mutations in codanin-1. American Journal of Human Genetics 71 1467-1474. (doi:10.1086/ 344781)

Filleur S, Hirsch J, Wille A, Schon M, Sell C, Shearer MH, Nelius T \& Wieland I 2009 INTS6/DICE1 inhibits growth of human androgenindependent prostate cancer cells by altering the cell cycle profile and Wnt signaling. Cancer Cell International 9 28. (doi:10.1186/1475-28679-28)

Geijsen N, Horoschak M, Kim K, Gribnau J, Eggan K \& Daley GQ 2004 Derivation of embryonic germ cells and male gametes from embryonic stem cells. Nature 427 148-154. (doi:10.1038/nature02247)

Handel MA \& Schimenti JC 2010 Genetics of mammalian meiosis: regulation, dynamics and impact on fertility. Nature Reviews Genetics 11 124-136. (doi:10.1038/nrg2723)

Held T, Paprotta I, Khulan J, Hemmerlein B, Binder L, Wolf S, Schubert S, Meinhardt A, Engel W \& Adham IM 2006 Hspa4l-deficient mice display increased incidence of male infertility and hydronephrosis development. Molecular and Cellular Biology 26 8099-8108. (doi:10.1128/MCB. 01332-06) 
Houlden H, Johnson J, Gardner-Thorpe C, Lashley T, Hernandez D, Worth P, Singleton AB, Hilton DA, Holton J, Revesz T et al. 2007 Mutations in TTBK2, encoding a kinase implicated in tau phosphorylation, segregate with spinocerebellar ataxia type 11. Nature Genetics 39 1434-1436. (doi:10.1038/ng.2007.43)

Houmard B, Small C, Yang L, Naluai-Cecchini T, Cheng E, Hassold T \& Griswold M 2009 Global gene expression in the human fetal testis and ovary. Biology of Reproduction 81 438-443. (doi:10.1095/biolreprod. 108.075747)

Hunt PA \& Hassold TJ 2002 Sex matters in meiosis. Science 296 2181-2183. (doi:10.1126/science.1071907)

Hunt PA \& Hassold TJ 2008 Human female meiosis: what makes a good egg go bad? Trends in Genetics 24 86-93. (doi:10.1016/j.tig.2007.11.010)

Kehrer-Sawatzki H, Wilda M, Braun VM, Richter HP \& Hameister H 2002 Mutation and expression analysis of the KRIT1 gene associated with cerebral cavernous malformations (CCM1). Acta Neuropathologica 104 231-240.

Kerrien S, Alam-Faruque Y, Aranda B, Bancarz I, Bridge A, Derow C, Dimmer E, Feuermann M, Friedrichsen A, Huntley R et al. 2007 IntAct open source resource for molecular interaction data. Nucleic Acids Research 35 D561-D565. (doi:10.1093/nar/gkl958)

Keshava Prasad TS, Goel R, Kandasamy K, Keerthikumar S, Kumar S, Mathivanan S, Telikicherla D, Raju R, Shafreen B, Venugopal A et al. 2009 Human Protein Reference Database - 2009 update. Nucleic Acids Research 37 D767-D772. (doi:10.1093/nar/gkn892)

Kimble J \& Page DC 2007 The mysteries of sexual identity. The germ cell's perspective. Science 316 400-401. (doi:10.1126/science.1142109)

Kuramochi-Miyagawa S, Kimura T, Ijiri TW, Isobe T, Asada N, Fujita Y, Ikawa M, Iwai N, Okabe M, Deng W et al. 2004 Mili, a mammalian member of piwi family gene, is essential for spermatogenesis. Development 131 839-849. (doi:10.1242/dev.00973)

Langfelder P \& Horvath S 2007 Eigengene networks for studying the relationships between co-expression modules. BMC Systems Biology 1 54. (doi:10.1186/1752-0509-1-54)

Lawson C, Gieske M, Murdoch B, Ye P, Li Y, Hassold T \& Hunt PA 2011 Gene expression in the fetal mouse ovary is altered by exposure to low doses of bisphenol A. Biology of Reproduction 84 79-86. (doi:10.1095/ biolreprod.110.084814)

Lecureuil C, Staub C, Fouchecourt S, Maurel MC, Fontaine I, Martinat N, Gauthier C, Daudignon A, Delaleu B, Sow A et al. 2007 Transferrin overexpression alters testicular function in aged mice. Molecular Reproduction and Development 74 197-206. (doi:10.1002/mrd.20523)

Li XC \& Schimenti JC 2007 Mouse pachytene checkpoint 2 (trip13) is required for completing meiotic recombination but not synapsis. PLoS Genetics 3 e130. (doi:10.1371/journal.pgen.0030130)

Liao BY \& Zhang J 2008 Null mutations in human and mouse orthologs frequently result in different phenotypes. PNAS 105 6987-6992. (doi:10. 1073/pnas.0800387105)

Lord PW, Stevens RD, Brass A \& Goble CA 2003 Investigating semantic similarity measures across the Gene Ontology: the relationship between sequence and annotation. Bioinformatics 19 1275-1283. (doi:10.1093/ bioinformatics/btg153)

Morelli MA \& Cohen PE 2005 Not all germ cells are created equal: aspects of sexual dimorphism in mammalian meiosis. Reproduction $\mathbf{1 3 0}$ 761-781. (doi:10.1530/rep.1.00865)

Nayernia K, Nolte J, Michelmann HW, Lee JH, Rathsack K, Drusenheimer N, Dev A, Wulf G, Ehrmann IE, Elliott DJ et al. 2006 In vitro-differentiated embryonic stem cells give rise to male gametes that can generate offspring mice. Developmental Cell 11 125-132. (doi:10. 1016/j.devcel.2006.05.010)

Olesen C, Moller M \& Byskov AG 2004 Tesmin transcription is regulated differently during male and female meiosis. Molecular Reproduction and Development 67 116-126. (doi:10.1002/mrd.20007)

Olesen C, Nyeng P, Kalisz M, Jensen TH, Moller M, Tommerup N \& Byskov AG 2007 Global gene expression analysis in fetal mouse ovaries with and without meiosis and comparison of selected genes with meiosis in the testis. Cell and Tissue Research 328 207-221. (doi:10.1007/ s00441-006-0205-5)

Ostlund G, Schmitt T, Forslund K, Kostler T, Messina DN, Roopra S, Frings O \& Sonnhammer EL 2010 InParanoid 7: new algorithms and tools for eukaryotic orthology analysis. Nucleic Acids Research 38 D196-D203. (doi:10.1093/nar/gkp931)
Roig I, Dowdle JA, Toth A, de Rooij DG, Jasin M \& Keeney S 2010 Mouse TRIP13/PCH2 is required for recombination and normal higher-order chromosome structure during meiosis. PLoS Genetics 6 e1001062. (doi:10.1371/journal.pgen.1001062)

Rolland AD, Lehmann KP, Johnson KJ, Gaido KW \& Koopman P 2011 Uncovering gene regulatory networks during mouse fetal germ cell development. Biology of Reproduction 84 790-800. (doi:10.1095/ biolreprod.110.088443)

Salwinski L, Miller CS, Smith AJ, Pettit FK, Bowie JU \& Eisenberg D 2004 The Database of Interacting Proteins: 2004 update. Nucleic Acids Research 32 D449-D451. (doi:10.1093/nar/gkh086)

Schlabach MR, Luo J, Solimini NL, Hu G, Xu Q, Li MZ, Zhao Z, Smogorzewska A, Sowa ME, Ang XL et al. 2008 Cancer proliferation gene discovery through functional genomics. Science 319 620-624. (doi:10.1126/science.1149200)

Schultz N, Hamra FK \& Garbers DL 2003 A multitude of genes expressed solely in meiotic or postmeiotic spermatogenic cells offers a myriad of contraceptive targets. PNAS $\mathbf{1 0 0} 12201-12206$. (doi:10.1073/pnas. 1635054100)

Shima JE, McLean DJ, McCarrey JR \& Griswold MD 2004 The murine testicular transcriptome: characterizing gene expression in the testis during the progression of spermatogenesis. Biology of Reproduction $\mathbf{7 1}$ 319-330. (doi:10.1095/biolreprod.103.026880)

Silva JM, Marran K, Parker JS, Silva J, Golding M, Schlabach MR, Elledge SJ, Hannon GJ \& Chang K 2008 Profiling essential genes in human mammary cells by multiplex RNAi screening. Science 319 617-620. (doi:10.1126/science.1149185)

Small CL, Shima JE, Uzumcu M, Skinner MK \& Griswold MD 2005 Profiling gene expression during the differentiation and development of the murine embryonic gonad. Biology of Reproduction 72 492-501. (doi:10. 1095/biolreprod.104.033696)

Soper SF, van der Heijden GW, Hardiman TC, Goodheart M, Martin SL, de Boer P \& Bortvin A 2008 Mouse maelstrom, a component of nuage, is essential for spermatogenesis and transposon repression in meiosis. Developmental Cell 15 285-297. (doi:10.1016/j.devcel.2008.05.015)

Stark C, Breitkreutz BJ, Reguly T, Boucher L, Breitkreutz A \& Tyers M 2006 BioGRID: a general repository for interaction datasets. Nucleic Acids Research 34 D535-D539. (doi:10.1093/nar/gkj109)

Thomson DM, Herway ST, Fillmore N, Kim H, Brown JD, Barrow JR \& Winder WW 2008 AMP-activated protein kinase phosphorylates transcription factors of the CREB family. Journal of Applied Physiology 104 429-438. (doi:10.1152/japplphysiol.00900.2007)

Watanabe T, Totoki Y, Toyoda A, Kaneda M, Kuramochi-Miyagawa S, Obata Y, Chiba H, Kohara Y, Kono T, Nakano T et al. 2008 Endogenous siRNAs from naturally formed dsRNAs regulate transcripts in mouse oocytes. Nature 453 539-543. (doi:10.1038/nature06908)

Wojtasz L, Daniel K, Roig I, Bolcun-Filas E, Xu H, Boonsanay V, Eckmann CR, Cooke HJ, Jasin M, Keeney S et al. 2009 Mouse HORMAD1 and HORMAD2, two conserved meiotic chromosomal proteins, are depleted from synapsed chromosome axes with the help of TRIP13 AAA-ATPase. PLoS Genetics 5 e1000702. (doi:10.1371/journal. pgen.1000702)

Yang F, Eckardt S, Leu NA, McLaughlin KJ \& Wang PJ 2008a Mouse TEX15 is essential for DNA double-strand break repair and chromosomal synapsis during male meiosis. Journal of Cell Biology 180 673-679. (doi:10.1083/jcb.200709057)

Yang F, Gell K, van der Heijden GW, Eckardt S, Leu NA, Page DC, Benavente R, Her C, Hoog C, McLaughlin KJ et al. $2008 \mathrm{~b}$ Meiotic failure in male mice lacking an X-linked factor. Genes and Development 22 682-691. (doi:10.1101/gad.1613608)

Yokoe T, Tanaka F, Mimori K, Inoue H, Ohmachi T, Kusunoki M \& Mori M 2008 Efficient identification of a novel cancer/testis antigen for immunotherapy using three-step microarray analysis. Cancer Research 68 1074-1082. (doi:10.1158/0008-5472.CAN-07-0964)

Yoshima T, Yura T \& Yanagi H 1998 Novel testis-specific protein that interacts with heat shock factor 2. Gene 214 139-146. (doi:10.1016/ S0378-1119(98)00208-X)

Received 18 July 2011

First decision 24 August 2011

Accepted 9 September 2011 